\title{
Weather and Crop Management Impact on Crop Yield Variability
}

\author{
Rezwanul Parvez ${ }^{1}$ \\ Nazea Hasan Khan Chowdhury ${ }^{2}$ (iD) \\ Research and Planning Associate, Community College of Denver, Denver, USA. \\ Email:rezwanulp@gmail.comTel:1-862-213-2333 \\ ${ }^{2}$ Faculty, Department of Business \& Information Technology, Front Range Community College, Boulder County \\ Campus, Longmont, USA. \\ Email:nazeaparvez@gmail.comTel:1-701-297-2857
}

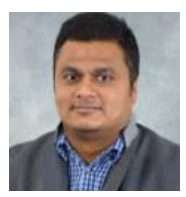

Corresponding Author

\begin{abstract}
This research is primarily designed to examine crop yield variation due to change in weather pattern and crop management activities by exploring a comprehensive list of factors (e.g. environmental, economic etc.). Given that existing literature indicates significant effects when farmland value is regressed on weather variables, a natural question is to ask whether major agricultural crop yields responds to change in historical weather pattern. To answer this question, this study relies on a state level panel dataset including agricultural and high-resolution weather data covering the period 1997-2018. Using a Seemingly Unrelated Regression (SUR) approach, this study estimates how crop spatial distribution patterns have impacted crop yield variation in response to weather in United States Greater Midwest region. Key findings indicate that changes in crop management activities correspond closely to estimate of both crop price and weather effects. Additionally, corn yield response to weather change varies with crop spatial distribution pattern, with distinct impacts on the magnitude and even the direction at the state level. Further, revenue of corn, soybeans, wheat and their respective lagged yields have positive and significant effect to respective crop yields. Finally, a major crop yield does vary across region due to variation of crop prices, precipitation and temperature. These findings have useful implications for agriculture sector on how historical weather trends have affected crop yield and distribution pattern.
\end{abstract}

Keywords: Crop yield, Seemingly unrelated regression, Crop spatial distribution, Weather pattern, Crop management, Greater Midwest.

Citation | Rezwanul Parvez; Nazea Hasan Khan Chowdhury (2020). Weather and Crop Management Impact on Crop Yield Variability. Agriculture and Food Sciences Research, 7(1): 7-15. History:

Received: 7 November 2019

Revised: 10 December 2019

Accepted: 13 January 2020

Published: 19 February 2020

Licensed: This work is licensed under a Creative Commons

Attribution 3.0 License $(\mathrm{cc})$ E

Publisher: Asian Online Journal Publishing Group
Acknowledgement: Both authors contributed to the conception and design of the study.

Funding: This study received no specific financial support.

Competing Interests: The authors declare that they have no conflict of interests.

Transparency: The authors confirm that the manuscript is an honest, accurate, and transparent account of the study was reported; that no vital features of the study have been omitted; and that any discrepancies from the study as planned have been explained.

Ethical: This study follows all ethical practices during writing.

\section{Contents}

1. Introduction ...8

2. Materials and Methods

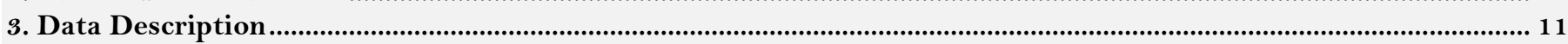

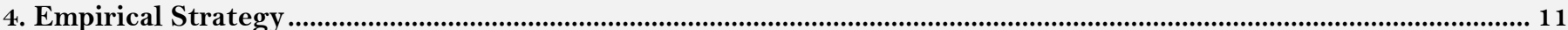

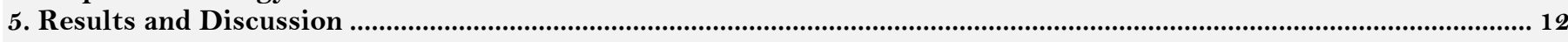

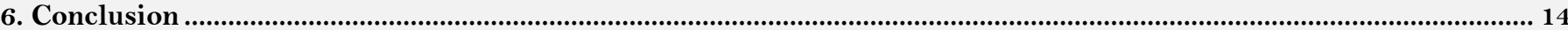

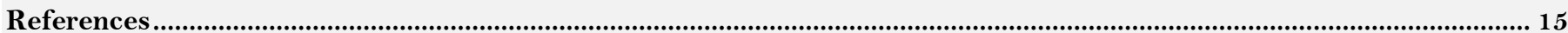




\section{Contribution of this paper to the literature}

This research is primarily designed to examine crop yield variation due to change in weather pattern and crop management activities by exploring a comprehensive list of factors (e.g. environmental, economic etc.).

\section{Introduction}

There has been a growing interest to examine the relation between crop productivity and weather change among advocates of weather change and food security, farmers, resource management professionals, and policy makers. A vast majority of existing literature primarily focused on investigating how crop yield respond to weather conditions, with emphasis on the decadal and interannual weather variability [1-3] weather extremes [4] vapor pressure deficits [5] atmospheric $\mathrm{CO} 2$ concentration [6] as well as weather variability [7]. Agricultural crop yield losses due to weather change are predicted to be as high as $82 \%$ by the end of $20^{\text {th }}$ century for some crops [8, 9$]$.

Weather change is defined as a temporal and spatial variation in the distribution of temperature and precipitation [10]. According to National Weather Assessment, the Upper Midwest (Minnesota, Wisconsin, Michigan, Iowa, South Dakota, and North Dakota) and the Northern Plains of U.S. have experienced more variation in temperatures and precipitation as compared to southern states [11]. The long-term weather trends picture can effectively signal farmers to adopt suitable cropping pattern. Existing literatures have listed multiple adaptation measures (i.e. planting dates shifting, switch crop patterns, develop new crops, shift in crop growing pattern) to mitigate the negative impacts and severity of weather on crop yield and production [12-15]. Agricultural producers tend to follow subsequent crop rotations to maximize crop production using lands with optimal water and nutrient storage conditions. Thus, it is useful to investigate how changes in crop spatial distribution patterns over time have impacted crop yield response to weather change in U.S. Greater Midwest?

Majority of literature have assumed that crop distribution in space remain constant over study period [16-18]. Empirical models (both process-based simulation models and statistical models) have been used to assess the potential impacts of weather on crop yields [19]. For example, a comprehensive data-driven analysis is developed to investigate crop pattern between counties in regulating corn yield response to weather change at the state level of U.S [20]. The issue of land use change and agricultural crop acreage response due to economic and biophysical factors is well documented focusing on Northern Great Plains agriculture [21, 22]. Thus, it would be useful to investigate how historical crop yields responded to economic and biophysical factors for Greater Midwest.

Here, the functional relationships between historical observation of weather patterns and agricultural crop yields (for corn, soybean and wheat) are examined at the state (11) level of Greater Midwest (i.e. Illinois, Indiana, Kansas, Michigan, Minnesota, Missouri, Nebraska, North Dakota, Ohio, South Dakota and Wisconsin) of the United States (U.S.). This paper addresses the key question of how agriculture adapts to weather change through crop yield loss patterns. The empirical challenge associated with measuring weather change impacts on crop yields centers around how to organize weather information relevant to farmers' cropping decision. This research developed a state-level panel of "weather data" to address this. The annual change in weather data for a state reflects knowledge on local weather. The yield variables are regressed on the weather data in a SUR panel estimation, controlling for trends and temporal effects to better examine the relation between yields and weather.

This study develops a set of weather indices to estimate crop yield response across regions to test the hypothesis of spatially varying weather change impacts. This paper makes three key contributions. First, as an initial rigorous empirical analysis of crop yield response to weather pattern change, it extends the knowledge on biophysical environment change impacts on agriculture and highlights the importance of considering yield variation in projections of future weather change impacts. Second, the summary contributes to the understanding of factors driving crop yield response. Third, the paper also builds on the economic literature of environmental adaptation by providing evidence of adaptation when the environmental change occurs gradually (e.g., [23, 24]).

The yield response model should generate more stable coefficients and yield predictions as compared to models including highly correlated weather variables. The historical pattern of crops (corn, soybean, wheat) price and yield for all 11 states of US Greater Midwest are presented in Figures 1- 11.

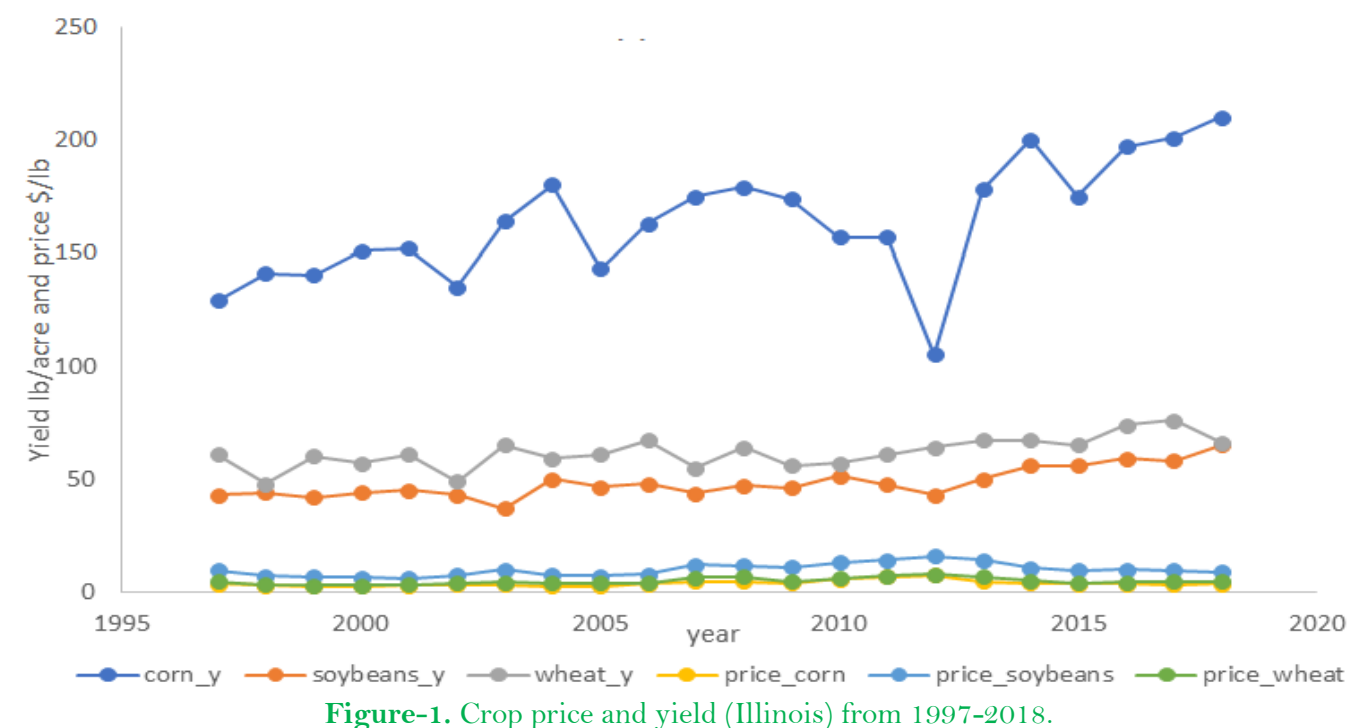




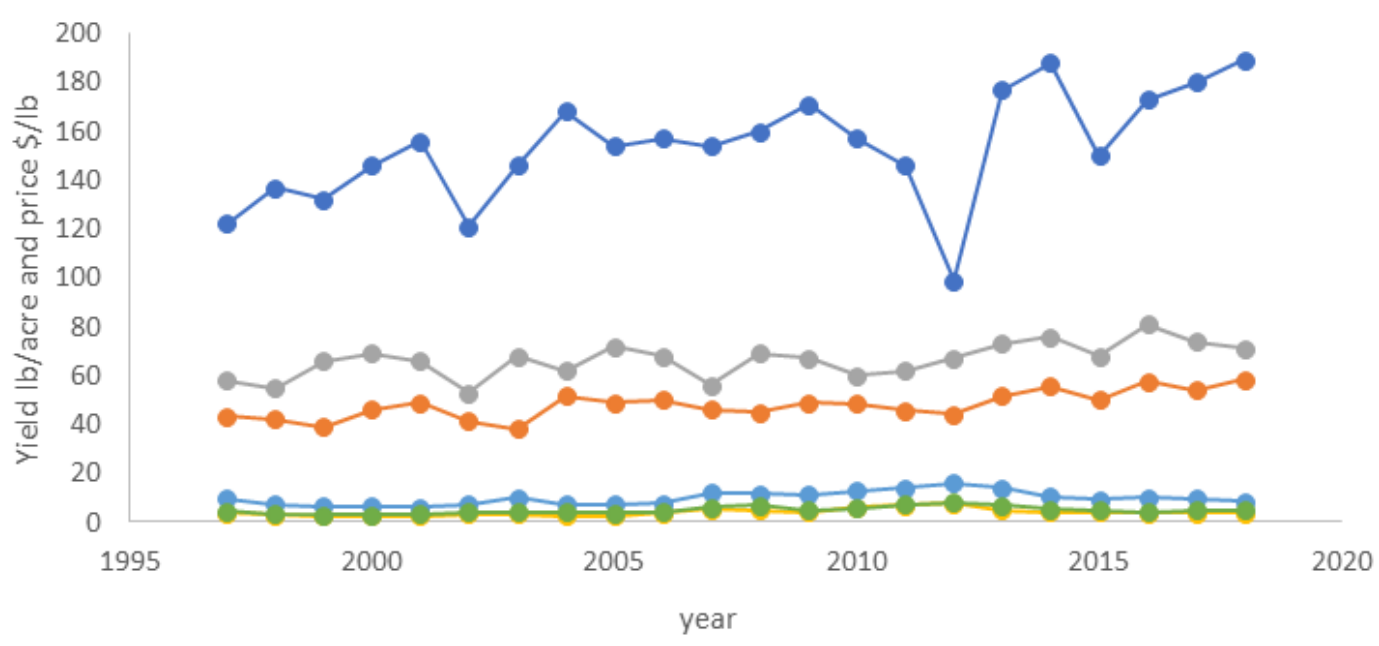

$\multimap$ corn_y $\longrightarrow$ soybeans_y $\longrightarrow$ wheat_y $\longrightarrow$ - price_corn $\multimap$ price_soybeans $\multimap$ price_wheat

Figure-2. Crop price and yield (Indiana) from 1997-2018.

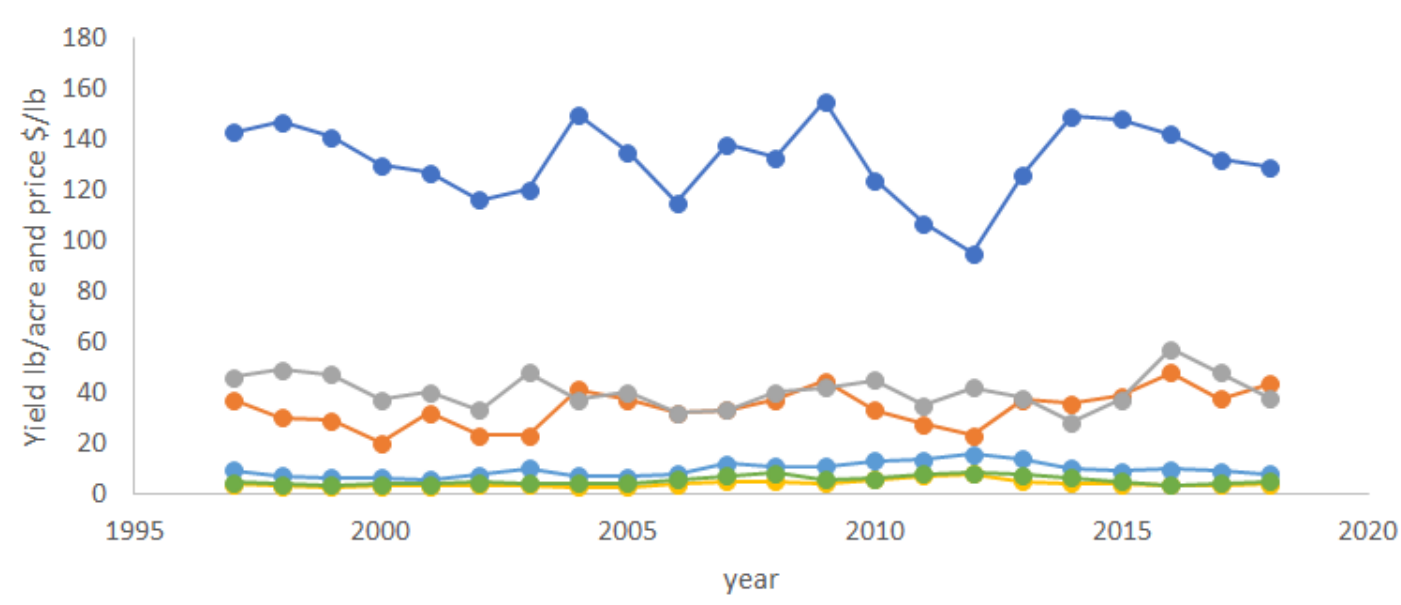

$\longrightarrow$ corn_y $\longrightarrow$ - soybeans_y $\longrightarrow$ wheat_y $\longrightarrow$ price_corn $\longrightarrow$ price_soybeans $\longrightarrow$ price_wheat

Figure-3. Crop price and yield (Kansas) from 1997-2018.
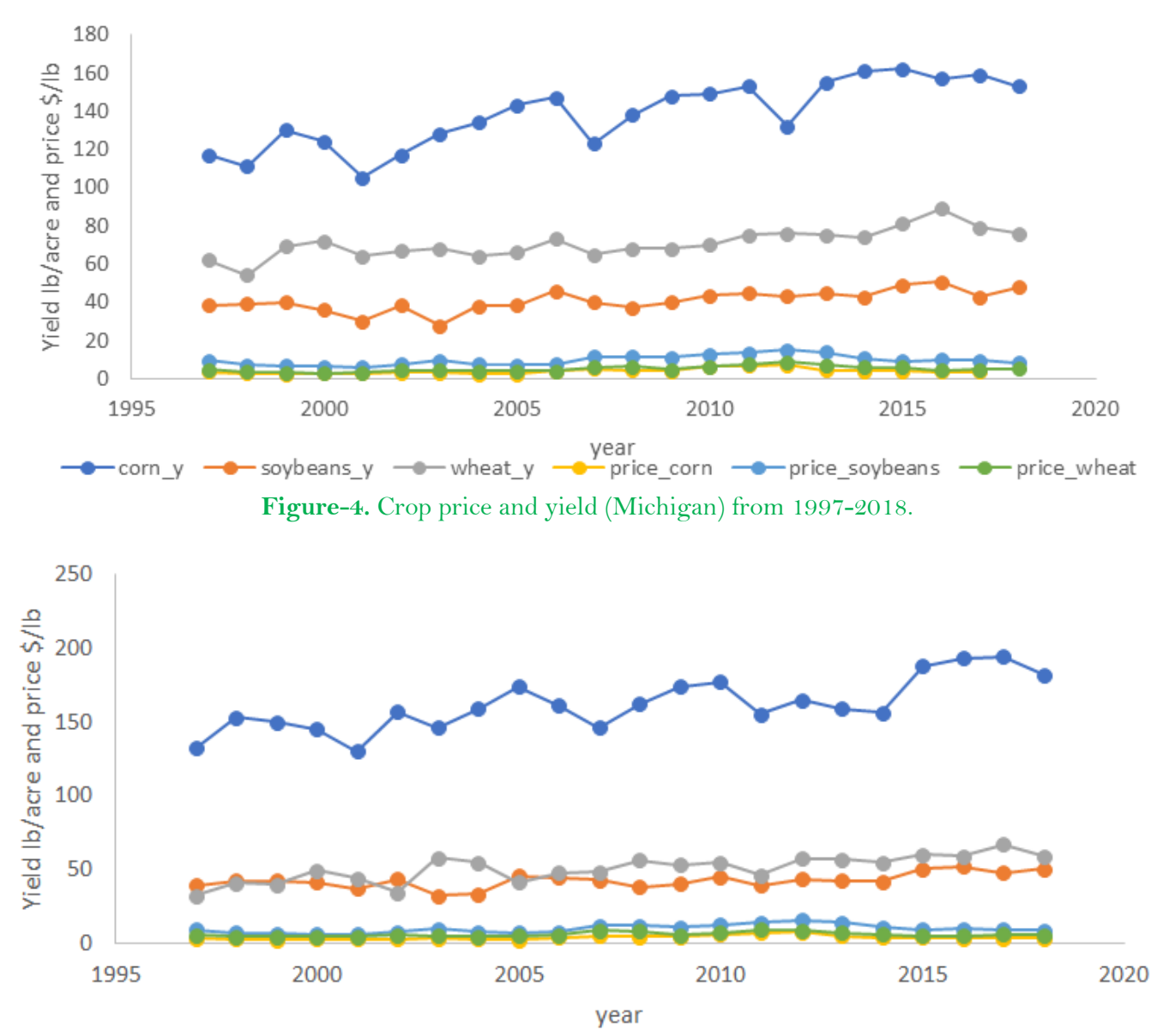

$\longrightarrow$ corn_y $\longrightarrow$ soybeans_y $\longrightarrow$ wheat_y $\longrightarrow$ price_corn $\longrightarrow-$ price_soybeans $\longrightarrow$ price_wheat Figure-5. Crop price and yield (Minnesota) from 1997-2018. 


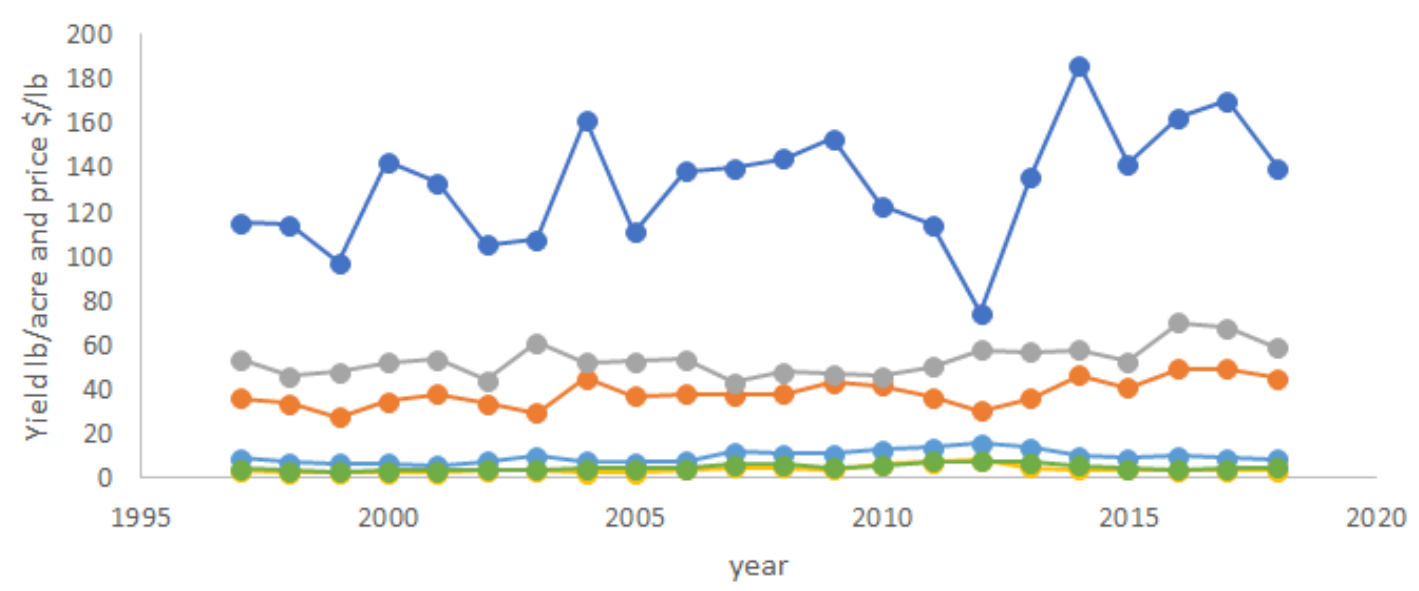

$\multimap-c o r n \_y \multimap$ soybeans_y $\longrightarrow$ wheat_y $\longrightarrow$ price_corn $\longrightarrow$ price_soybeans $\longrightarrow$ price_wheat

Figure-6. Crop price and yield (Missouri) from 1997-2018.

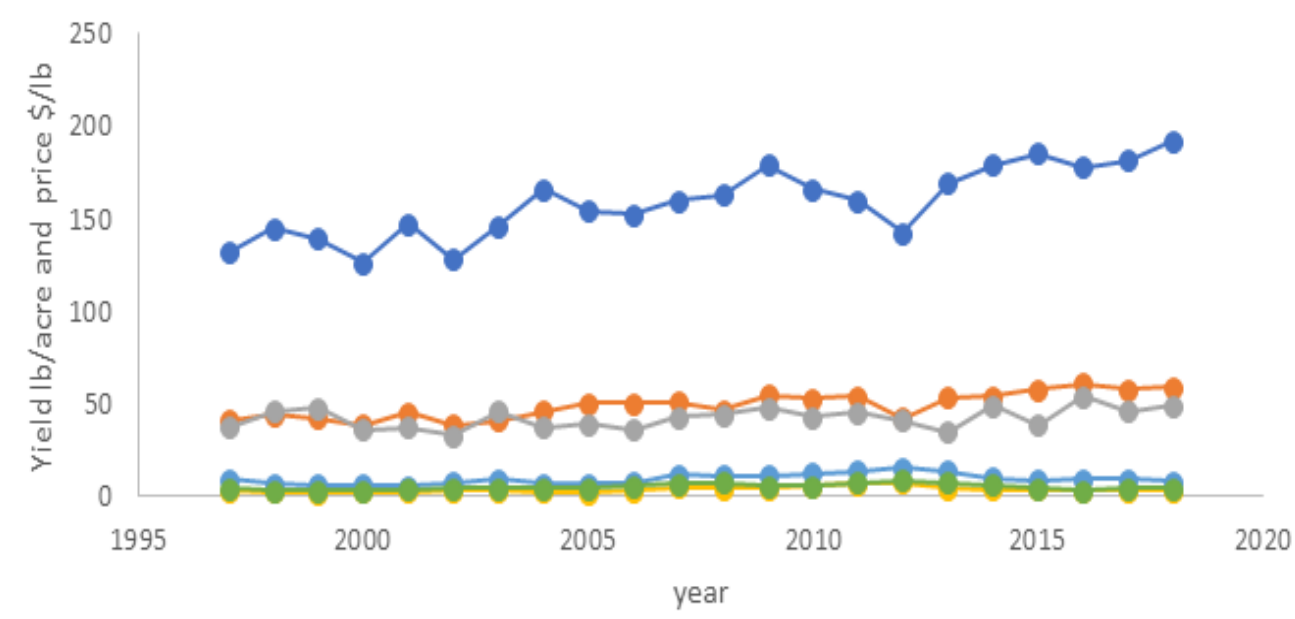

$\multimap$ corn_y $\rightarrow$-soybeans_y $\rightarrow$ wheat_y $\longrightarrow$ - price_corn $\rightarrow$ price_soybeans $\rightarrow$ price_wheat

Figure-7. Crop price and yield (Nebraska) from 1997-2018.

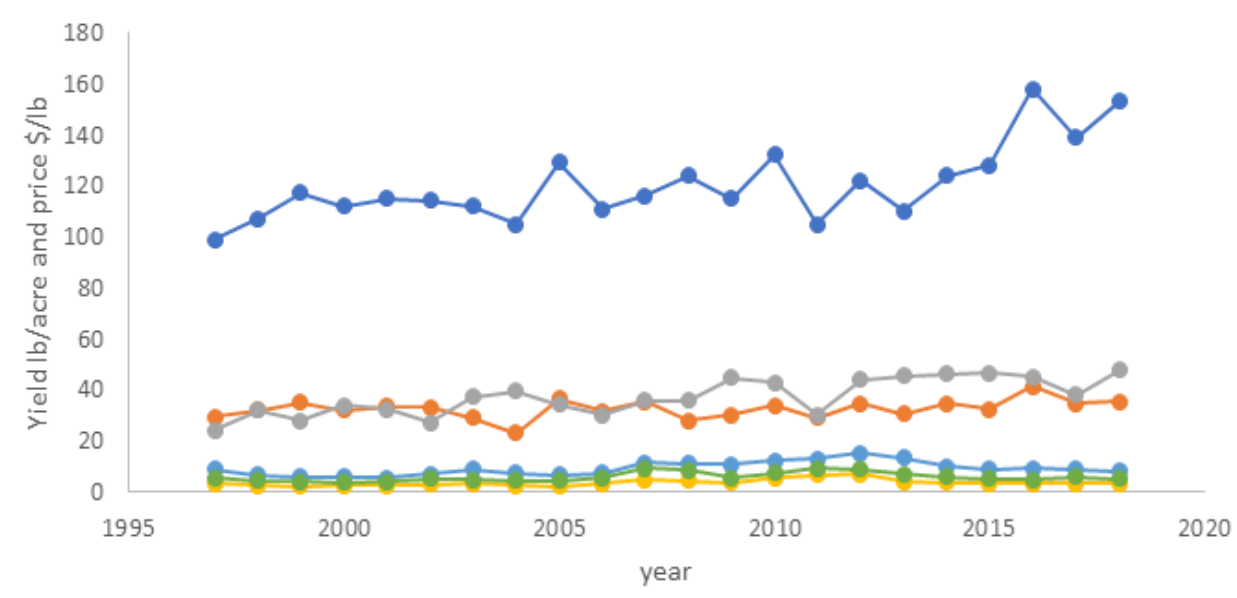

$\rightarrow$ corn_y $\rightarrow-$ soybeans_y $\rightarrow-$ wheat_y $\rightarrow$ price_corn $\rightarrow$ price_soybeans $\rightarrow$ price_wheat

Figure-8. Crop price and yield (North Dakota) from 1997-2018.

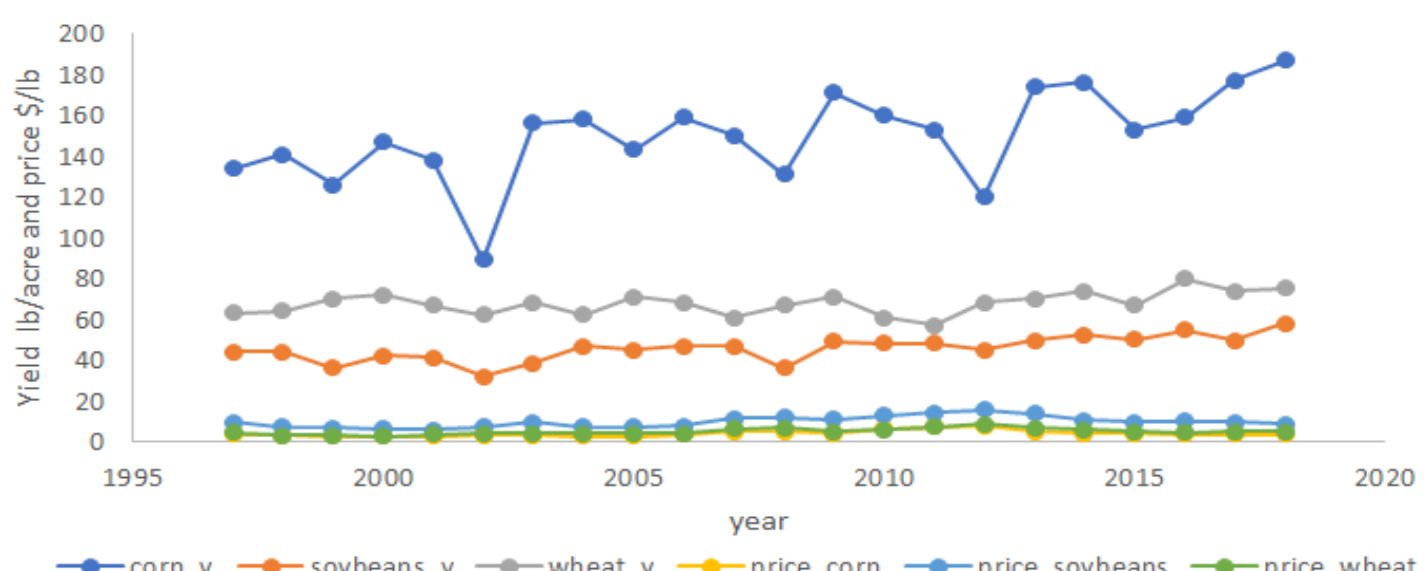

Figure-9. Crop price and yield (Ohio) from 1997-2018. 


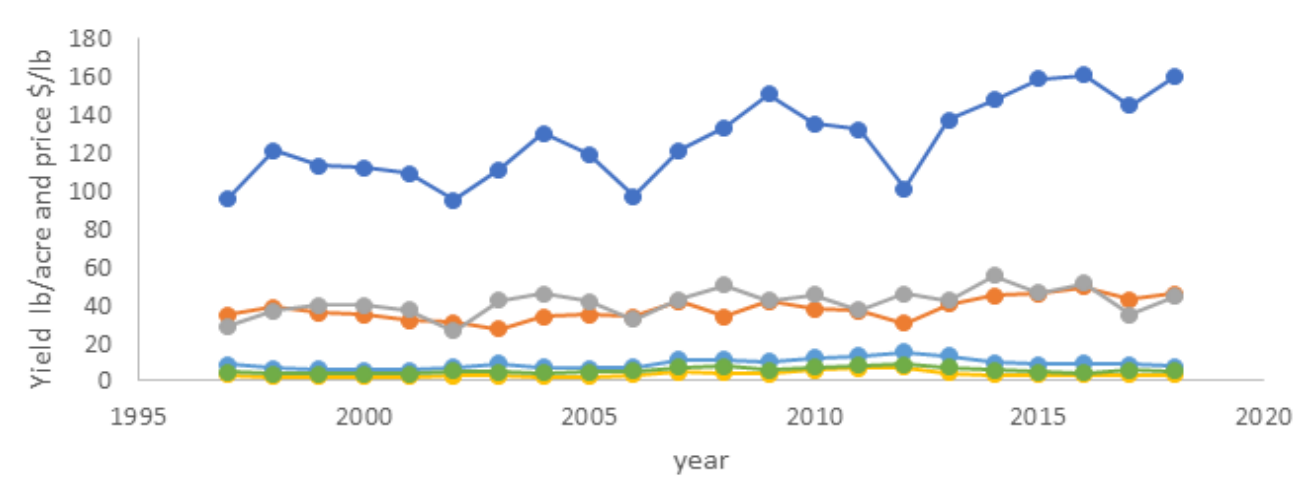

$\longrightarrow$ corn_y $\longrightarrow$ soybeans_y $\longrightarrow$ wheat_y $\longrightarrow$ price_corn $\longrightarrow$ price_soybeans $\multimap$ price_wheat

Figure-10. Crop price and yield (South Dakota) from 1997-2018.

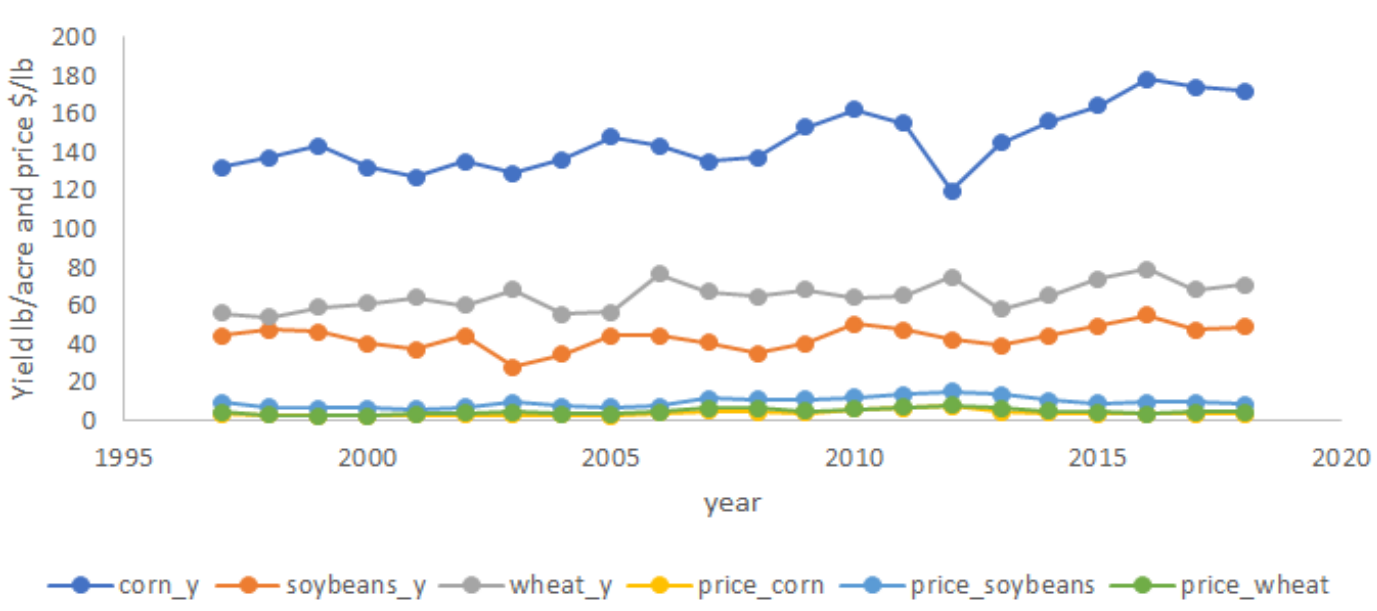

Figure-11. Crop price and yield (Wisconsin) from 1997-2018.

Understanding the connection among major crop yields, crop prices, weather, and other input prices are vital to stakeholders who are concerned with addressing weather change and improving global food security. Also, researchers and policy-makers are deeply engaged to better understand the effects of weather change on the agricultural landscape of the greater Midwest. The importance of estimating functional relationships between historical observations of weather and yields are well cited in scientific literature. The results discussed here will help forecast future crop yield trends in response to change in weather pattern. Further, this research will help policy-makers and producers make better-informed crop production decisions in a changing weather scenario.

\section{Materials and Methods}

This section empirically examines the effects of weather change (weather factors like monthly average precipitation and temperature, lagged crop prices,) on multiple crops yields (corn, soybeans, wheat) loss. The weather data is constructed to investigate weather trends at the state level. The functional relationship is presented on how crop yields (current year) correlate with current and last year crop prices, lag crop yields, crop revenue, and weather variables like precipitation, temperature, using longitudinal data. Here, dependent variables of the stated regression model for each three major crop choices (corn, wheat, and soybean) are measured at yield per bushel. Further, a seemingly unrelated regression (SUR) approach is employed with spatial autoregressive terms to capture the weather effects on crop yield loss.

This is because statistical models including only on spatial variation (i.e. cross-sectional studies) are very prone to omitted variable bias, whereas those including only on temporal variation (i.e. time series studies) are often subject to significant errors in estimates of temperature sensitivity. These errors can happen due to limited temporal variation in temperature compared to other weather variables, as well as strong temporal correlation between temperature and rainfall or radiation.

\section{Data Description}

The analyses presented in this study compiles agricultural and climatologic data. State-level annual data on crop yields are collected from NASS surveys from 1997 to 2018. Weather data (e.g. precipitation and temperature) for the month of March, April, May, June, July, and August for last 22 years come from the National Climatic Data Center [25]. Information on prices and yields of corn, soybeans, and wheat for all eleven Midwest states (e.g. North Dakota, South Dakota, Nebraska, Minnesota, Iowa, Missouri, Wisconsin, Illinois, Kansas, Michigan, Indiana, and Ohio) for the period 1997 to 2018 year are obtained from the Census of Agriculture (United States Department of Agricultural, National Agricultural Statistics Service). Major crops (e.g. corn, soybeans, and wheat) yield and price data are lagged. Prices data are adjusted for inflation using GDP Price deflator (2017 as base year). The GDP price deflator data are collected from the Federal Reserve Economic Data, Economic Research Division. Crops (e.g. corn, soybeans, and wheat) revenue are also calculated using yield and price information.

\section{Empirical Strategy}

The empirical strategy relies on employing a Seemingly Unrelated Regression (SUR) model to examine the marginal effects of weather factor change on agricultural crop yield at the state level. A "full information maximum likelihood" approach is used to examine the effects. The right-hand side of estimated regression equations includes 
no endogenous variables and assume correlation of error term among equations. Heteroskedasticity is also almost certain since presence of multiple dependent variables. The regression equations can be expressed in the form of stacked regression.

$$
Y=X \beta+u
$$

Where, $\mathrm{Y}$ is a set of dependent variables of crop (corn, soybeans and wheat) yields. $\mathrm{X}$ is a set of independent variables (crop prices, precipitation, and temperature for the month of March, April, May, June, July, and August, crop revenue etc.). Further, $u$ is error term. $\beta$ is parameter estimates in the proposed model.

\section{Results and Discussion}

Summary statistics are reported in Table 1. The estimation results of Equation 1 are reported in Tables 2-4. The underlying identification assumption is that a state experiencing change in weather pattern would have changed its management activities of agricultural crops differently from a state not experiencing any change, after purging off state-level trends and nation-level shocks.

Table-1. Summary statistics.

\begin{tabular}{l|c|c|c|c|c}
\hline Variable name & Observation & Mean & Standard deviation & Min & Max \\
\hline corn_yield & 242 & 143.98 & 24.45 & 75.00 & 210.00 \\
\hline soybeans_yield & 242 & 41.79 & 8.05 & 20.00 & 65.00 \\
\hline wheat_yield & 242 & 54.28 & 13.82 & 24.30 & 89.00 \\
\hline price_corn & 242 & 3.83 & 1.36 & 2.18 & 7.92 \\
\hline price_soybeans & 242 & 9.49 & 2.65 & 5.48 & 15.87 \\
\hline price_wheat & 242 & 5.12 & 1.54 & 2.47 & 9.07 \\
\hline Lagged yield_corn & 231 & 142.76 & 23.80 & 75.00 & 201.00 \\
\hline Lagged yield_soybeans & 231 & 41.37 & 7.79 & 20.00 & 61.00 \\
\hline Lagged yield_wheat & 231 & 54.03 & 13.82 & 24.30 & 89.00 \\
\hline Precipitation_March & 242 & 2.07 & 1.32 & 0.15 & 6.81 \\
\hline Precipitation_April & 242 & 3.12 & 1.57 & 0.50 & 9.61 \\
\hline Precipitation_May & 242 & 3.96 & 1.51 & 0.81 & 9.60 \\
\hline Precipitation_june & 242 & 4.28 & 1.58 & 1.29 & 9.44 \\
\hline Precipitation_July & 242 & 3.50 & 1.37 & 0.75 & 8.18 \\
\hline Precipitation_august & 242 & 3.32 & 1.21 & 0.62 & 6.94 \\
\hline Temperature_march & 242 & 36.73 & 8.13 & 16.30 & 58.10 \\
\hline Temperature_april & 242 & 48.32 & 6.08 & 31.30 & 60.90 \\
\hline Temperature_may & 242 & 59.24 & 5.05 & 47.40 & 72.50 \\
\hline Temperature_june & 242 & 68.65 & 4.32 & 59.10 & 78.10 \\
\hline Temperature_july & 242 & 73.34 & 4.19 & 63.50 & 84.90 \\
\hline Temperature_august & 242 & 71.31 & 4.16 & 60.90 & 83.00 \\
\hline Revenue_corn & 242 & 550.62 & 203.35 & 245.97 & 1188.02 \\
\hline Revenue_soybeans & 242 & 398.84 & 138.72 & 124.43 & 721.18 \\
\hline Revenue_wheat & 242 & 275.30 & 103.92 & 109.63 & 648.94 \\
\hline
\end{tabular}

Table-2. Results of seemingly unrelated regression (Corn equation).

\begin{tabular}{|c|c|c|}
\hline \multicolumn{3}{|c|}{ Dependent variable: Corn yield } \\
\hline Explanatory variables & Coefficient and standard deviation & P-value \\
\hline Price_corn & $\begin{array}{c}-0.29^{* * *} \\
(1.33) \\
\end{array}$ & 0.00 \\
\hline Price_soybeans & $\begin{array}{c}0.78 \\
(0.80) \\
\end{array}$ & 0.33 \\
\hline Price_wheat & $\begin{array}{c}0.16 \\
(0.90)\end{array}$ & 0.86 \\
\hline Lagged yield_corn & $\begin{array}{c}0.11 * * * \\
(0.04)\end{array}$ & 0.00 \\
\hline Lagged yield_soybeans & $\begin{array}{c}0.04 \\
(0.12) \\
\end{array}$ & 0.70 \\
\hline Lagged yield_wheat & $\begin{array}{l}0.020 \\
(0.07)\end{array}$ & 0.78 \\
\hline Precipitation_march & $\begin{array}{l}-0.36 \\
(0.45) \\
\end{array}$ & 0.42 \\
\hline Precipitation_April & $\begin{array}{l}-0.58 \\
(0.39)\end{array}$ & 0.14 \\
\hline Precipitation_May & $\begin{array}{l}-0.27 \\
(0.33)\end{array}$ & 0.41 \\
\hline Precipitation_June & $\begin{array}{l}-0.36 \\
(0.34)\end{array}$ & 0.29 \\
\hline Precipitation_july & $\begin{array}{l}0.72^{*} \\
(0.38\end{array}$ & 0.06 \\
\hline Precipitation_August & $\begin{array}{l}1.07^{* *} \\
(0.43)\end{array}$ & 0.01 \\
\hline Temperature_March & $\begin{array}{c}0.29 * * * \\
(0.11)\end{array}$ & 0.01 \\
\hline Temperature_April & $\begin{array}{l}-0.02 \\
(0.14)\end{array}$ & 0.92 \\
\hline Temperature_May & $\begin{array}{l}0.34^{*} \\
(0.18) \\
\end{array}$ & 0.06 \\
\hline Temperature_June & $\begin{array}{c}0.13 \\
(0.24)\end{array}$ & 0.59 \\
\hline Temperature_July & $\begin{array}{c}0.20 \\
(0.28) \\
\end{array}$ & 0.46 \\
\hline Temperature_august & $\begin{array}{c}-0.73^{* * *} \\
(0.22) \\
\end{array}$ & 0.00 \\
\hline Revenue_corn & $0.19^{* * * *}$ & 0.00 \\
\hline
\end{tabular}




\begin{tabular}{l|c|c}
\hline & $(0.009)$ & 0.86 \\
\hline Revenue_soybeans & $\begin{array}{l}0.002 \\
(0.01)\end{array}$ & 0.68 \\
\hline Revenue_wheat & $\begin{array}{l}0.005 \\
(0.01)\end{array}$ & 0.00 \\
\hline Constant & $\begin{array}{c}109.85^{* * *} \\
(14.40)\end{array}$ \\
\hline Tote: The symbols ******, and *
\end{tabular}

Note: The symbols ***, **, and $*$ indicate statistical significance at $\alpha=0.01, \alpha=0.05$, and $\alpha=0.10$, respectively

Numbers in parentheses are the standard errors of the parameter estimates.

Table-3. Results of seemingly unrelated regression (Soybean Equation).

\begin{tabular}{|c|c|c|}
\hline \multicolumn{3}{|c|}{ Dependent variable: Soybeans yield } \\
\hline Explanatory variables & Coefficient and standard deviation & P-value \\
\hline Price_corn & $\begin{array}{c}0.33 \\
(0.36) \\
\end{array}$ & 0.35 \\
\hline Price_soybeans & $\begin{array}{c}3.67 * * * \\
(0.22)\end{array}$ & 0.00 \\
\hline Price_wheat & $\begin{array}{c}0.12 \\
(0.24)\end{array}$ & 0.61 \\
\hline Lagged yield_corn & $\begin{array}{l}-0.010 \\
(0.010)\end{array}$ & 0.34 \\
\hline Lagged yield_soybeans & $\begin{array}{c}0.12^{* * *} \\
(0.03)\end{array}$ & 0.00 \\
\hline Lagged yield_wheat & $\begin{array}{c}0.02 \\
(0.02)\end{array}$ & 0.26 \\
\hline Precipitation_march & $\begin{array}{l}-0.04 \\
(0.12)\end{array}$ & 0.76 \\
\hline Precipitation_April & $\begin{array}{l}-0.13 \\
(0.11)\end{array}$ & 0.21 \\
\hline Precipitation_May & $\begin{array}{c}0.07 \\
(0.09) \\
\end{array}$ & 0.43 \\
\hline Precipitation_June & $\begin{array}{l}(0.03) \\
(0.09)\end{array}$ & 0.74 \\
\hline Precipitation_july & $\begin{array}{c}0.13 \\
(0.10) \\
\end{array}$ & 0.20 \\
\hline Precipitation_August & $\begin{array}{c}(0.47)^{* * *} \\
(0.11)\end{array}$ & 0.00 \\
\hline Temperature_March & $\begin{array}{c}0.04 \\
(0.03)\end{array}$ & 0.18 \\
\hline Temperature_april & $\begin{array}{c}-0.04 \\
(0.040)\end{array}$ & 0.30 \\
\hline Temperature_May & $\begin{array}{c}0.04 \\
(0.05)\end{array}$ & 0.41 \\
\hline Temperature_June & $\begin{array}{c}0.09 \\
(0.06)\end{array}$ & 0.16 \\
\hline Temperature_July & $\begin{array}{c}0.06 \\
(0.07)\end{array}$ & 0.45 \\
\hline Temperature_august & $\begin{array}{c}-0.17 * * * \\
(0.06)\end{array}$ & 0.00 \\
\hline Revenue_corn & $\begin{array}{l}-0.002 \\
(0.002)\end{array}$ & 0.44 \\
\hline Revenue_soybeans & $\begin{array}{c}0.09 * * * \\
(0.003)\end{array}$ & 0.00 \\
\hline Revenue_wheat & $\begin{array}{l}-0.004 \\
(0.003) \\
\end{array}$ & 0.18 \\
\hline Constant & $\begin{array}{c}32.84 * * * * \\
(3.88)\end{array}$ & 0.00 \\
\hline
\end{tabular}

Note: The symbols **** indicate statistical significance at $\alpha=0.01$.

Numbers in parentheses are the standard errors of the parameter estimates.

The SUR approach used here includes longitudinal panel data for eleven Midwest states of three major crop yields over 22 years (1997-2018). Key findings indicated, in all three-crop yield equation, price of soybeans positively related to its respective yields whereas corn and wheat prices are negatively related to its respective yields Tables 2-4. Also, the relationship between crop yield and prices are statistically significant. In addition, lagged price of corn and wheat also negatively related to their respective yields. Last year corn yields positively related to current year corn yields and also statistically significant. Furthermore, revenue of corn also positively related to corn yields and also statistically significant. Moreover, soybeans revenue and lagged yields also positively related to soybeans yields and statistically significant. Further, wheat revenue and lagged yields also positively related to its current year yield and statistically significant. Together with regional trends in temperature and precipitation, these estimates can partly explain the crop expansion pattern over the past few decades. For instance, higher yield of corn, soybeans, and wheat have coincided with increase in both temperature and precipitation in the Dakotas and the Upper Midwest. This association has a particularly vital implication given the relatively large marginal effects estimated for this region. These results are also in line with the historical movements of corn location discussed [26, 27]. 
Table-4. Results of seemingly unrelated regression (Wheat Equation).

\begin{tabular}{|c|c|c|}
\hline \multicolumn{3}{|c|}{ Dependent variable: Wheat yield } \\
\hline Explanatory variables & Coefficient and standard deviation & P-value \\
\hline Price_corn & $\begin{array}{c}-0.26 \\
(0.68) \\
\end{array}$ & 0.70 \\
\hline Price_soybeans & $\begin{array}{c}0.96 \\
(0.41)\end{array}$ & 0.02 \\
\hline Price_wheat & $\begin{array}{c}-8.58^{* * * *} \\
0.46\end{array}$ & 0.00 \\
\hline Lagged yield_corn & $\begin{array}{r}-0.04 * * \\
(0.020)\end{array}$ & 0.02 \\
\hline Lagged yield_soybeans & $\begin{array}{c}0.17 * * * \\
(0.06)\end{array}$ & 0.00 \\
\hline Lagged yield_wheat & $\begin{array}{l}0.18^{* * *} * \\
(0.03)\end{array}$ & 0.00 \\
\hline Precipitation_march & $\begin{array}{l}-0.28 \\
(0.23)\end{array}$ & 0.22 \\
\hline Precipitation_April & $\begin{array}{l}0.009 \\
(0.20)\end{array}$ & 0.96 \\
\hline Precipitation_May & $\begin{array}{c}0.25 \\
(0.17) \\
\end{array}$ & 0.14 \\
\hline Precipitation_June & $\begin{array}{l}-0.16 \\
(0.17)\end{array}$ & 0.36 \\
\hline Precipitation_july & $\begin{array}{l}0.32^{*} \\
(0.19)\end{array}$ & 0.10 \\
\hline Precipitation_August & $\begin{array}{c}0.78 * * * \\
(0.22)\end{array}$ & 0.00 \\
\hline Temperature_March & $\begin{array}{c}0.03 \\
(0.06)\end{array}$ & 0.61 \\
\hline Temperature_april & $\begin{array}{l}-0.04 \\
(0.07)\end{array}$ & 0.63 \\
\hline Temperature_May & $\begin{array}{l}-0.07 \\
(0.09)\end{array}$ & 0.44 \\
\hline Temperature_June & $\begin{array}{c}0.06 \\
(0.12)\end{array}$ & 0.63 \\
\hline Temperature_July & $\begin{array}{c}-0.003 \\
(0.14)\end{array}$ & 0.98 \\
\hline Temperature_august & $\begin{array}{l}0.008 \\
(0.11)\end{array}$ & 0.94 \\
\hline Revenue_corn & $\begin{array}{c}0.004 \\
(0.005)\end{array}$ & 0.37 \\
\hline Revenue_soybeans & $\begin{array}{c}-0.01 * * \\
(0.006)\end{array}$ & 0.03 \\
\hline Revenue_wheat & $\begin{array}{c}0.15^{* * *} * \\
(0.006)\end{array}$ & 0.00 \\
\hline Constant & $\begin{array}{c}39.21 * * * \\
(7.34)\end{array}$ & 0.00 \\
\hline
\end{tabular}

Note: The symbols $* * * * *$, and $*$ indicate statistical significance at $\alpha=0.01, \alpha=0.05$, and $\alpha=0.10$, respectively. Numbers in parentheses are the standard errors of the parameter estimates.

Average precipitation (March, April, May, June) are found to be negatively related to corn yields because preplanting time and during planting time precipitation adversely effects crop yield. In soybean equation, precipitation (for the month of March and April) are negatively related to soybeans yields as we expected. On the other hand, precipitation July and August are positively related to soybeans yields. In wheat equation, precipitation (for the month of March and June) negatively related to wheat yields. Precipitation (for the month of July and August) are positively related to wheat yields. Temperature also significantly affects crop yield pattern. In corn equation, temperature (for the month of March and May) are positively related and statistically significant to corn yields for current year. the average temperature (for the month of August) are negatively related and statistically significant to corn yield. In soybean equation, average temperature (for the month of April and August) are negatively related to soybeans yield in current year and statistically significant Table 3. This is because producers expect positive temperature for optimal growth of soybeans crop and yields before and during planting season. In wheat equation, average temperature (for the month of March and August) are positively related to wheat yield Table 4.

\section{Conclusion}

The issue of weather change impacts on crop yields variability is well discussed by existing literature. All else equal, the heterogeneity of multiple crop yield responses also implies a change in relative profitability per acre. As weather change persists, this will slowly alter cropping patterns. This study analyzes the importance of taking crop yield effects into consideration when evaluating weather pattern change impacts on agriculture. The scenario of adjustment and adaptation in crop acreage by producers is important and need to be included in policy discussion to avoid imprecise and even unrealistic projections of future crop losses due to weather change. The findings reported here are useful to see how yield responds to different economic and biophysical factors (e.g. crop prices, lagged yields and prices, crop revenue, temperature, precipitation). Results also indicate that precipitation before planting season has impact on crop yield. The impact of average temperature on crop yields is evident. Further, crop revenue, lagged yields of corn, wheat, and soybeans are positively related to current year yields. Moreover, prices of corn and wheat negatively related to current year yield. Factors like precipitation (for the month of 
March) have negative effect on yields of corn, wheat, and soybeans. Also, temperature (for the month of March) positively related to yields of corn, wheat, and soybeans. The findings discussed here will help policy makers, researchers, producers, and landowners making more informed cropping decision as a response to change in weather as well as economic factors affecting crop yields.

This research work has few limitations too. First, this analysis only highlights reduced-form relationship between weather pattern and crop yields and does not include other technological and socioeconomic drivers of crop patterns. Second, the nature of data determines the crop yields shift are not directly observed at a field level. Third, this study only focuses on a selected number of field crops (corn, soybean, and wheat) excluding all other agricultural crops. Future research is needed to incorporate plant characteristics, cultivation practices, farm management strategies, producers' decision making behavior and other factors for more robust analyses.

\section{References}

[1] E. J. Colville, A. E. Carlson, B. L. Beard, R. G. Hatfield, J. S. Stoner, A. V. Reyes, and D. J. Ullman, "Sr-Nd-Pb isotope evidence for ice-sheet presence on Southern Greenland during the last interglacial," Science, vol. 333, pp. 620-623, 2011.

[2] W. Schlenker and M. J. Roberts, "Nonlinear temperature effects indicate severe damages to US crop yields under climate change," Proceedings of National Academy of Sciences, USA, vol. 106, pp. 15594-15598, 2009.Available at: https://doi.org/10.1073/pnas.0906865106.

[3] L. You, M. W. Rosegrant, S. Wood, and D. Sun, "Impact of growing season temperature on wheat productivity in China," Agricultural and Forest Meteorology, vol. 149, pp. 1009-1014, 2009.Available at: https://doi.org/10.1016/j.agrformet.2008.12.004. C. Lesk, P. Rowhani, and N. Ramankutty, "Influence of extreme weather disasters on global crop production," Nature, vol. 529, pp. 84-87, 2016.Available at: https://doi.org/10.1038/nature 16467.

[5] J. D. Ray, R. W. Gesch, T. R. Sinclair, and L. H. Allen, "The effect of vapor pressure deficit on maize transpiration response to a drying soil," Plant and Soil, vol. 239, pp. 113-121, 2002.

[6] G. Sakurai, T. Iizumi, M. Nishimori, and M. Yokozawa, "How much has the increase in atmospheric $\mathrm{CO} 2$ directly affected past soybean production?," Scientific Reports, vol. 4, pp. 1-4, 2014.

[7] G. Leng, X. Zhang, M. Huang, G. R. Asrar, and L. R. Leung, "The role of climate covariability on crop yields in the conterminous United States," Scientific Reports, vol. 6, pp. 1-11, 2016.Available at: https://doi.org/10.1038/srep33160.

[8] M. Gammans, P. Mérel, and A. Ortiz-Bobea, "Negative impacts of climate change on cereal yields: Statistical evidence from France," Environmental Research Letters, vol. 12, pp. 1-9, 2017.

[9] B. Schauberger, S. Archontoulis, A. Arneth, J. Balkovic, P. Ciais, D. Deryng, J. Elliott, C. Folberth, N. Khabarov, and C. Müller, "Consistent negative response of US crops to high temperatures in observations and crop models," Nature Communications, vol. 8, pp. 1-9, 2017.Available at: https://doi.org/10.1038/ncomms13931.

[10] S. Hsiang, "Climate econometrics," Annual Review of Resource Economics, vol. 8, pp. 43-75, 2016.

[11] J. M. Melillo, T. Richmond, and G. Yohe, "Climate change impacts in the United States," Third National Climate Assessment2014.

[12] T. M. Osborne and T. R. Wheeler, "Evidence for a climate signal in trends of global crop yield variability over the past 50 years," Environmental Research Letters, vol. 8, pp. 1-9, 2013.Available at: https://doi.org/10.1088/1748-9326/8/2/024001.

[13] A. S. Cohn, L. K. VanWey, S. A. Spera, and J. F. Mustard, "Cropping frequency and area response to climate variability can exceed yield response," Nature Climate Change, vol. 6, pp. 601-604, 2016.Available at: https://doi.org/10.1038/nclimate2934.

[14] A. J. Challinor, J. Watson, D. B. Lobell, S. Howden, D. Smith, and N. Chhetri, "A meta-analysis of crop yield under climate change and adaptation," Nature Climate Change, vol. 4, pp. 287-291, 2014.Available at: https://doi.org/10.1038/nclimate2 153.

[15] K. Waha, C. Müller, A. Bondeau, J. P. Dietrich, P. Kurukulasuriya, J. Heinke, and H. Lotze-Campen, "Adaptation to climate change through the choice of cropping system and sowing date in Sub-Saharan Africa," Global Environmental Change, vol. 23, pp. 130-143, 2013.Available at: https://doi.org/10.1016/j.gloenvcha.2012.11.001.

[16] S. Asseng, F. Ewert, and P. Martre, "Rising temperatures reduce global wheat production," Nature Clim Change, vol. 5, pp. 143$147,2015$.

[17] T. Lizumi, J.-J. Luo, A. J. Challinor, G. Sakurai, M. Yokozawa, H. Sakuma, M. E. Brown, and T. Yamagata, "Impacts of El Niño Southern oscillation on the global yields of major crops," Nature Communications, vol. 5, pp. 1-7, 2014.Available at: https://doi.org/10.1038/ncomms4712.

[18] B. Liu, S. Asseng, C. Müller, F. Ewert, J. Elliott, D. B. Lobell, P. Martre, A. C. Ruane, D. Wallach, and J. W. Jones, "Similar estimates of temperature impacts on global wheat yield by three independent methods," Nature Climate Change, vol. 6, pp. 11301136, 2016.Available at: https://doi.org/10.1038/nclimate3115.

[19] D. B. Lobell and M. B. Burke, "On the use of statistical models to predict crop yield responses to climate change," Agricultural and Forest Meteorology, vol. 150, pp. 1443-1452, 2010.Available at: https://doi.org/10.1016/j.agrformet.2010.07.008.

[20] G. Leng and M. Huang, "Crop yield response to climate change varies with crop spatial distribution pattern," Scientific Reports, vol. 7, pp. 1-10, 2017.Available at: https://doi.org/10.1038/s41598-017-01599-2.

[21] R. Parvez, B. D. Madurapperuma, and D. Ripplinger, "Modeling land use pattern change analysis in the Northern Great Plains: A novel approach," presented at the Presented as a paper at Agricultural and Applied Economics Association (AAEA) \& Western Agricultural Economics Association (WAEA) Joint Annual Meeting, San Francisco, CA, 2015.

[22] R. Parvez, D. C. Roberts, and D. Ripplinger, "Factors impacting crop acreage decision: A case study of North Dakota agriculture," Agricultural Development, vol. 3, pp. 16-36, 2018.Available at: https://doi.org/10.20448/journal.523.2018.31.16.36.

[23] R. Hornbeck, "The enduring impact of the American Dust Bowl: Short-and long-run adjustments to environmental catastrophe," American Economic Review, vol. 102, pp. 1477-1507, 2012.Available at: https://doi.org/10.1257/aer.102.4.1477.

[24] R. Hornbeck and K. Pinar, "The historically evolving impact of the ogallala aquifer: Agricultural adaptation to groundwater and drought," American Economic Journal: Applied Economics, vol. 6, pp. 190-219, 2014.Available at: https://doi.org/10.1257/app.6.1.190.

[25] National Climatic Data Center, "National Centers for Environmental Information, Asheville NC 28801-5001, USA." Retrieved from: https://www.ncdc.noaa.gov/, https://www1.ncdc.noaa.gov/pub/data/cirs/climdiv/?C=M;O=D, 2018.

[26] A. L. Olmstead and P. W. Rhode, "Adapting North American wheat production to climatic challenges, 1839-2009," Proceedings of the National Academy of Sciences, vol. 108, pp. 480-485, 2011 .Available at: https://doi.org/10.1073/pnas. 1008279108.

[27] J. M. Beddow and P. G. Pardey, "Moving matters: The effect of location on crop production," The Journal of Economic History, vol. 75, pp. 219-249, 2015.Available at: https://doi.org/10.1017/s002205071500008x. 